\title{
Propriedades mecânicas e análise microestrutural de um concreto produzido com agregado da região Amazônica brasileira
}

\author{
Mechanical properties and microstructural \\ analysis of a concrete produced with \\ aggregate from the Brazilian Amazon \\ region
}

\author{
Agostinho Alves de Oliveira Júnior ${ }^{1}$, Maurílio Gomes Pimentel ${ }^{1}$ \\ Marcelo de Sousa Picanço ${ }^{1}$
}

\author{
${ }^{1}$ Rua Augusto Corrêa, 01, Universidade Federal do Pará, Programa de Pós-Graduação em Engenharia Civil, Guamá, \\ 66075-110, Belém, PA, Brasil. \\ e-mail: agostinho.junior@ifap.edu.br,mauriliogp@ufpa.br, marcelosp@ufpa.br
}

\section{RESUMO}

Em virtude da escassez de agregado em algumas regiões na Amazônia, o presente trabalho tem como objetivo, avaliar as propriedades de concretos produzidos com agregado proveniente do leito do rio Oiapoque. Fazendo um estudo comparativo relacionando as características entre os agregados graúdos utilizados na construção civil, em especial o material encontrado no leito do Rio Oiapoque, na cidade de Oiapoque-AP, e o agregado graúdo oriundo da região metropolitana de Belém. Foram realizados ensaios para avaliação das propriedades mecânicas, ensaios de desempenho e microestrutura dos concretos. Os resultados mostraram que a utilização do agregado de origem arenítica da região de Oiapoque não apresentou diferença na resistência à compressão e no módulo de elasticidade dos concretos em relação ao concreto produzidos com agregado disponibilizado comercialmente na região metropolitana de Belém, além disso não houve diferença entre os concretos quanto à taxa de absorção de cloretos ao longo do tempo e avanço na frente de carbonatação. A microestrutura eletrônica de varredura dos concretos, apresentaram uma microestrutura densa, mas normalmente encontrada em compósitos formulados à base de matriz cimentícias. Esses achados servem como evidências empíricas para a validação da utilização de uma jazida de agregado na Região Amazônica, contribuindo para o desenvolvimento de obras de infraestrutura na região.

Palavras-chave: Escassez de agregado, região amazônica, propriedades mecânicas, propriedades de durabilidade.

\begin{abstract}
Due to the scarcity of aggregates in some regions of the Amazon, the present work has the objective of evaluating the properties of concretes produced with aggregate from the bed of the Oiapoque river. A comparative study was carried out comparing the characteristics of the large aggregates used in construction, especially the material found in the Oiapoque river bed in the city of Oiapoque, and the large aggregate from the metropolitan area of Belém. mechanical properties, performance tests and microstructure of concretes. The results showed that the use of the aggregate of arenite origin of the Oiapoque region showed no difference in the compressive strength and modulus of elasticity of the concretes in relation to the concrete produced with aggregate commercially available in the metropolitan area of Belém. the concrete as to the rate of absorption of chlorides over time and neither advance in the front of carbonation. The scanning electron microstructure of the concretes presented a dense microstructure, but usually found in cementitious matrix - based composites. These findings serve as empirical evidence for the validation of the use of an aggregate deposit in the Amazon Region, contributing to the development of infrastructure works in the region.
\end{abstract}

Keywords: Aggregate scarcity, Amazon region, mechanical properties, durability properties. 


\section{INTRODUÇÃO}

O volume global de recursos naturais utilizados nas obras de edificações e transportes aumentou em 23 vezes desde 1900 até o ano de 2010 [1], desses recursos os agregados compõem a maior parte dos insumos, compondo o grupo de materiais mais extraídos em todo o mundo. Além disso, cerca de $66 \%$ da população mundial será urbana até o ano de 2050, um aumento que corresponde a 2,5 bilhões de pessoas [2], se esse aumento da população desencadear em um consumo acelerado dos recursos naturais, isso pode se tornar um contribuinte para a escassez de agregados para as obras de construção civil e infraestrutura até $\mathrm{o}$ ano de 2050.

De fato, a escassez de agregados para as construções de obras de infraestrutura e transporte, já tem se tornado um problema emergente com grandes implicações sociopolíticas, econômicas e ambientais [3], causando conflitos sociais e políticos na Índia [4], e impactos ambientais devido a mineração extensiva em diversos lugares do mundo [3]. Em todas as regiões brasileiras há mineração de areias e rochas para produção de brita. Entretanto, em vastas áreas da Região Norte as rochas próprias para britagem são escassas, devido principalmente ao extenso manto sedimentar [5] que encobre as reservas possíveis de serem aproveitadas economicamente. Para a produção de agregados graúdos nessa região são explorados os raros maciços cristalinos nos estados do Amapá (AP), Roraima e Amazonas, lateritos e cascalhos no Maranhão. Dentre esses estados, destaca-se o Amapá, que tem um polo produtor principal de areia, cascalho e brita nos municípios de Porto Grande e Ferreira Gomes, que abastecem os dois maiores centros urbanos do estado: Macapá e Santana. Há ainda um pequeno polo de extração artesanal de areia a $70 \mathrm{~km}$ da capital, no município de Itaubal. Ademais, é também desenvolvida a extração nos municípios de Laranjal do Jari e Oiapoque, pois estão muito distantes do polo de Porto Grande.

O seixo é extraído em vários pontos no leito do rio Araguari numa distância entre 3,5 e $14 \mathrm{~km}$ da cidade Porto Grande. O material é extraído por, pelo menos, quatro empresas estabelecidas no local. Consiste em minério caracterizado por seixos finos a médios angulosos, de coloração amarelo avermelhada e predominantemente de quartzo. Como o material já é previamente selecionado durante a extração, o teor de estéril (areia) é muito pequeno, comumente de 5 a $8 \%$.

O procedimento de lavra se dá através do uso de balsas que se deslocam até o local de extração. A partir da mesma utiliza-se um conjunto de motor bomba para dragar a carga sedimentar do fundo do rio. $\mathrm{O}$ material dragado passa por uma tela que seleciona o material de maior granulometria (seixo). O minério é trazido de balsa até o local de desembarque que é feito através de pá carregadeira ou com uso de motor bomba. A operação de lavra e desembarque pode durar em média entre três e quatros horas, sendo que diariamente podem ser realizadas de duas (verão) até quatro (inverno) viagens por dia. Cada frente de lavra conta com dois a quatro operários, geralmente sendo dois mergulhadores e um ou dois auxiliares braçais.

Diferentemente da extração de seixo em terra firme, neste segmento o funcionamento é regular, praticamente durante todo o ano, inclusive em regime de extração maior durante o inverno, pois o deslocamento e as condições de trabalho são mais seguros e a disponibilidade de material também é maior. Desta forma, o desempenho social em termos de geração de emprego e remuneração é melhor do que na extração de seixo e areia em terra firme, embora ainda seja ressalvada a informalidade dos empregados.

Além do polo extrativista de agregados de Porto Grande há outros locais também utilizados para lavra destes materiais, quer seja em função da disponibilidade (Areal Bela Vista - Macapá) quer seja pela grande distância de Porto Grande, como no caso dos municípios de Laranjal do Jari e Oiapoque no Estado do Amapá. A cidade de Oiapoque situa-se em região de difícil acesso, afastada dos centros consumidores e com severas restrições ambientais de exploração. Isso exige, muitas vezes, o transporte rodoviário de brita a distâncias de até $500 \mathrm{~km}$ utilizando-se infraestrutura de transportes precária e ineficiente. Essa escassez de agregados granítico imprime um aumento considerável nos custos da construção civil na região, o que torna atraente economicamente a extração de agregado no leito do Rio Oiapoque. O agregado é utilizado desconhecendo-se suas características físicas, químicas ou mecânicas na produção de concreto. Percebe-se então pertinente a necessidade de se estudar as propriedades desse material, com o intuito de melhor aproveitamento, trazendo informações técnicas e segurança para os usuários (técnicos e construtores da região), e contribuir com o crescimento da atividade econômica naquela região.

Em face de pouca disponibilidade de agregado na região, o presente trabalho tem como objetivo, avaliar as propriedades de concretos produzidos com agregado proveniente do leito do rio Oiapoque. Fazendo um estudo comparativo relacionando as características entre os agregados graúdos utilizados na construção civil, em especial o material encontrado no leito do Rio Oiapoque, na cidade de Oiapoque-AP, e o agregado graúdo oriundo da região metropolitana de Belém, por esse ser o mais utilizado e estudado por pesquisadores na região. 


\section{MATERIAIS E MÉTODOS}

No presente trabalho, para avaliar as propriedades de um concreto produzido com um agregado de origem arenítica, proveniente da região provinciana de Oiapoque - AP, utilizou-se um concreto controle, também produzido com agregado de origem arenítica, utilizado na região metropolitana de Belém no estado do Pará.

\subsection{Materiais}

Como materiais, utilizou-se o agregado graúdo de origem arenítica proveniente da região provinciana de Oiapoque - AP, e um agregado também de origem arenítica proveniente do município de Ourém - PA, comercializado na região metropolitana de Belém - PA. O agregado miúdo utilizado, foi uma areia de rio de origem quartzosa. Apesar dos agregados graúdos possuírem a mesma origem mineralógica, suas composições granulométricas são diferentes (Tabela 1; Figura 1), sendo que o agregado comercializado na região metropolitana de Belém - PA apresenta um diâmetro máximo maior que o agregado objeto do presente estudo, entretanto, suas massas específicas e absorção de água são iguais. A água utilizada era potável com $\mathrm{pH} 6,0$ e temperatura de $28^{\circ} \mathrm{C}$. O cimento utilizado foi o CP IV - 32 [6], com massa específica de $3,09 \mathrm{~g} / \mathrm{cm}^{3}$.

Tabela 1: Caracterização física dos agregados, A é a absorção de água, MF é o módulo de finura e DM é o diâmetro máximo dos agregados.

\begin{tabular}{l|l|l|l|l|l}
\hline \multicolumn{1}{c|}{ AGREGADO } & MASSA ESPECíFICA (g/cm $\mathbf{3})$ & MASSA UNITÁRIA $\mathbf{( g / \mathbf { c m } ^ { 3 } )}$ & A (\%) & MF & DM $(\mathbf{m m})$ \\
\hline Agregado miúdo & 2,63 & 1,50 & - & 1,78 & 1,20 \\
\hline Agregado de Oiapoque & 2,62 & 1,53 & 5,1 & 5,18 & 9,50 \\
\hline Agregado de Belém & 2,62 & 1,66 & 5,1 & 6,53 & 19,00 \\
\hline
\end{tabular}

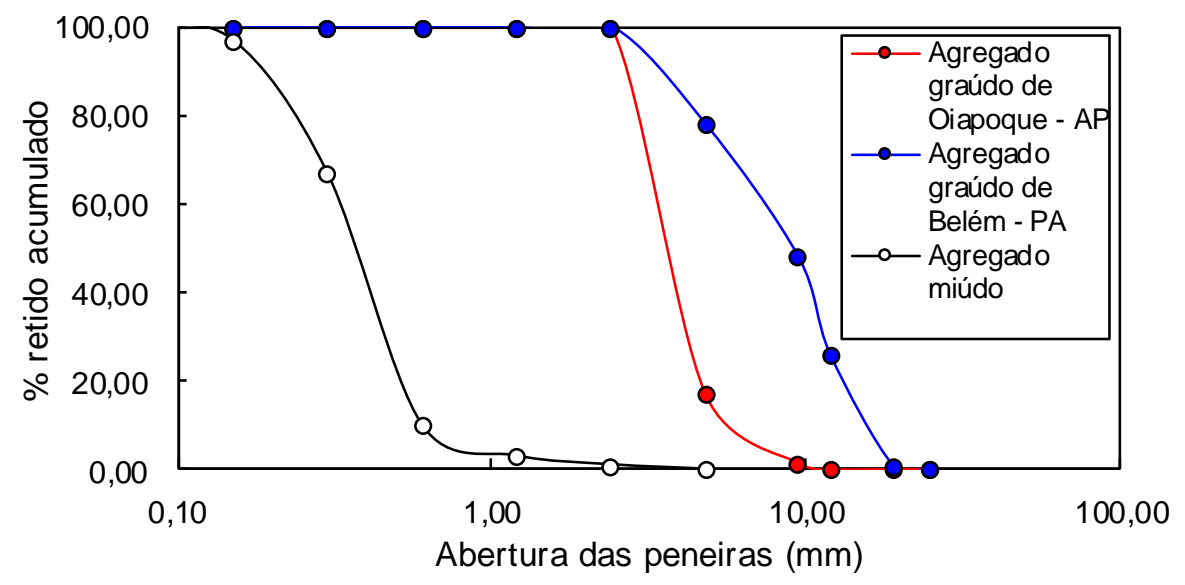

Figura 1: Curva granulométrica dos agregados.

\subsection{Métodos}

Para avaliar as propriedades mecânicas, de desempenho, mineralógica e microestruturais dos concretos com o agregado de origem arenítica da região de Oiapoque - AP, confeccionou-se um concreto de referência com teor de argamassa de 53\% e relação água aglomerante de 0,5 , que no presente estudo será mencionado como Belém, por este ser fabricado com o agregado graúdo disponibilizado comercialmente na região metropolitana de Belém. Em seguida, confeccionou-se um concreto com as mesmas condições do de referência (Belém), mas com a utilização em 100\% do agregado graúdo proveniente da região de Oiapoque - AP, por conta disso, esse concreto será referido no presente estudo como Oiapoque. Os detalhes do consumo dos materiais em $\mathrm{kg} / \mathrm{m}^{3}$, encontram-se na Tabela 2, curiosamente, eles apresentam o mesmo consumo de materiais devido aos agregados apresentarem o mesmo valor de massa específica (Tabela 1). 
Tabela 2: Consumo dos materiais em $\mathrm{kg} / \mathrm{m}^{3}$.

\begin{tabular}{l|l|l|l|l}
\hline CONCRETO & CIMENTO & AGREGADO MIÚDO & AGREGADO GRAÚDO & ÁGUA \\
\hline Oiapoque & 366,45 & 798,87 & 1033,40 & 183,23 \\
\hline Belém & 366,45 & 798,87 & 1033,40 & 183,23 \\
\hline
\end{tabular}

Os concretos foram confeccionados em uma betoneira de eixo inclinado com capacidade para 150 litros. Os componentes do concreto foram pesados e adicionados na betoneira. Primeiramente, adicionouse o agregado graúdo pré-misturado com parte da água de mistura em $30 \mathrm{~s}$, em seguida, adicionou-se o agregado miúdo natural e misturou-se por mais $30 \mathrm{~s}$. Finalmente, adicionou-se o cimento juntamente com o restante da água misturada com o aditivo e o concreto foi misturado por mais 5 min, resultando em um período de mistura total de $6 \mathrm{~min}$. O controle das misturas foi realizado de acordo com a NBR NM 67 [7], o abatimento foi fixado em $70 \pm 20 \mathrm{~mm}$. Após a mistura e medida do abatimento, os concretos foram adicionados em moldes cilíndricos (100 mm x $200 \mathrm{~mm}$ ) e deixados em ambiente de laboratório por um período de $24 \mathrm{~h}$. Posteriormente eles foram desmoldados e colocados à cura imersa em água saturada com hidróxido de cálcio $\left(\mathrm{Ca}(\mathrm{OH})_{2}\right)$, com temperatura de $28 \pm 2{ }^{\circ} \mathrm{C}$ até a idade de ensaio. Todos os ensaios foram realizados na idade de 28 dias.

As variáveis respostas para verificação da caracterização mecânica dos concretos foram a resistência à compressão, realizada de acordo com a NBR 5739 [8], e o módulo de elasticidade, realizado de acordo com NBR 8522 [9].

A absorção de cloretos foi realizada de acordo com a TC 166-PCD (RILEM, 1999) [10]. Para determinar a absorção de cloretos capilar, realizou-se uma adaptação do procedimento. As amostras passaram por secagem em estufa a $100 \pm 5^{\circ} \mathrm{C}$ até alcançarem constância de massa o que levou um intervalo de tempo de 48 horas. Em seguida as amostras foram colocadas em dessecadores a temperatura ambiente de laboratório de $28 \pm 5^{\circ} \mathrm{C}$ por um intervalo de tempo de 24 horas, posteriormente as amostras foram vedadas lateralmente com adesivo a base de epóxi e colocadas em repouso em dessecadores por 48 horas. Só então, as amostras foram submetidas ao ensaio de absorção de cloretos.

As amostras foram submersas parcialmente em uma solução de cloretos a $3 \%$, a solução alcançava uma altura de $5 \mathrm{~mm}$ medidas a partir da base das amostras, sendo antes da submersão parcial registrada a massa seca de cada amostra, consequentemente as amostras foram pesadas nos intervalos de 0h (massa seca), 10 minutos, $1,4 \mathrm{~h}$ e $24 \mathrm{~h}$ registrando os resultados.

Quanto à análise de carbonatação, esta foi realizada de acordo com o procedimento da especificação TC 116-PCD (RILEM, 1999) [11]. As amostras passaram por um período de sazonamento em ambiente de laboratório com umidade relativa do ar de $94 \%$ e temperatura de $30 \pm 5^{\circ} \mathrm{C}$ por um período de 2 dias, em seguida as amostras foram mantidas em estufa por um período de 48 horas em temperatura de $80 \pm 5^{\circ} \mathrm{C}$ até constância de massa, posteriormente as amostras foram expostas em ambiente de laboratório novamente a temperatura de $28 \pm 5^{\circ} \mathrm{C}$. Finalmente as amostras foram armazenadas em uma câmara de carbonatação em uma concentração de $\mathrm{CO}_{2}$ de $5 \%$ em um intervalo de tempo de 7 dias. Após procedimento supracitado as amostras foram cisalhadas transversalmente em uma prensa hidráulica com uma aplicação de carga de $0,25 \mathrm{MPa} / \mathrm{s}$, logo em seguida ao cisalhamento borrifou-se nas amostras solução de fenolftaleína a $1 \%$ para leitura da profundidade de carbonatação, sendo esta última medida com um paquímetro digital de precisão em um intervalo de tempo de 24 horas.

Para verificar as fases mineralógicas presentes na zona de transição dos concretos, foram recolhidas amostras de argamassa aderida ao agregado de ambos os concretos, em seguida essas amostras foram secas em temperatura de $60^{\circ} \mathrm{C}$ e destorroadas para pulverização. A análise de DRX foi realizada em um difratômetro de feixe divergente equipado com um goniômetro $\theta-\theta$, um tubo de raios-X de $\mathrm{Cu}$ com radiação de $\mathrm{Cu}(\mathrm{K} \alpha 1=1,540598 \AA$ ), um filtro de $\mathrm{Ni} \mathrm{K} \beta$. As condições do instrumento foram as

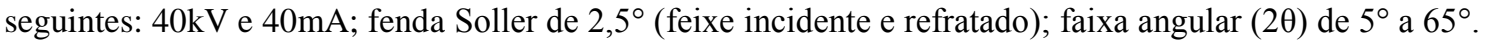
A coleta dos difratogramas foi realizada com passo angular de $0,02^{\circ}$ e tempo por passo de $0,5 \mathrm{~s}^{\circ}$, fenda divergente de $0,6 \mathrm{~mm}$.

A avaliação da análise microestrutura do concreto, foi realizada por microscopia eletrônica de varredura (MEV), as amostras foram preparadas com extração dos fragmentos e fixação em um suporte de fita de carbono $(\mathrm{C})$ e metalizadas com ouro $(\mathrm{Au})$. As análises foram realizadas utilizando-se imagens secundárias obtidas a $20 \mathrm{kV}$, com uma distância de trabalho de $15 \mathrm{~mm}$. Além disso, foi realizado o mapeamento dos elementos por energia dispersiva (EDS). 


\subsection{Análise dos dados}

Para os dados quantitativos, estes foram analisados quanto à sua normalidade e homocedasticidade, utilizando o teste de Shapiro-Wilk e Levene respectivamente. Confirmando-se a normalidade e homocedasticidade, estes foram analisados, utilizando-se o teste $\mathrm{t}$ de Student para amostras independentes, pois havia apenas duas condições experimentais. Não houve exclusão de nenhum dado da análise estatística. Os dados estão apresentados como média \pm desvio padrão. Foram consideradas diferenças significativas, quando $\mathrm{P}<0,05$.

\section{RESULTADOS E DISCUSSÃO}

A resistência à compressão dos concretos produzidos com o agregado de Oiapoque apresentou-se semelhante a resistência à compressão dos concretos produzidos com o agregado comercializado na região metropolitana de Belém (teste $\mathrm{T}$ não pareado; $\mathrm{t}(4)=0,600 ; \mathrm{P}=0,580 ;$ Fig. 2 . a), além de ter apresentado menor dispersão em torno da média quando comparado com os concretos de Belém. $\mathrm{O}$ módulo de elasticidade também apresentou-se estatisticamente igual entre os concretos (teste $\mathrm{T}$ não pareado; $\mathrm{t}(2)=0,070 ; \mathrm{P}=0,950 ;$ Fig. 2 . b). A média da resistência à compressão para o concreto de Oiapoque foi de 16,09 MPa e a média do módulo foi de 24,93 GPa. Entretanto, o concreto do presente estudo, que utilizou um agregado de origem arenítica em sua composição (seixo-rolado), não se mostrou de acordo com os padrões do modelo de representação da NBR 6118 (ABNT, 2014) [12] (Fig. 2. c), que estima a relação entre resistência à compressão e a rigidez do concreto de acordo com o agregado que foi utilizado para sua fabricação.

a

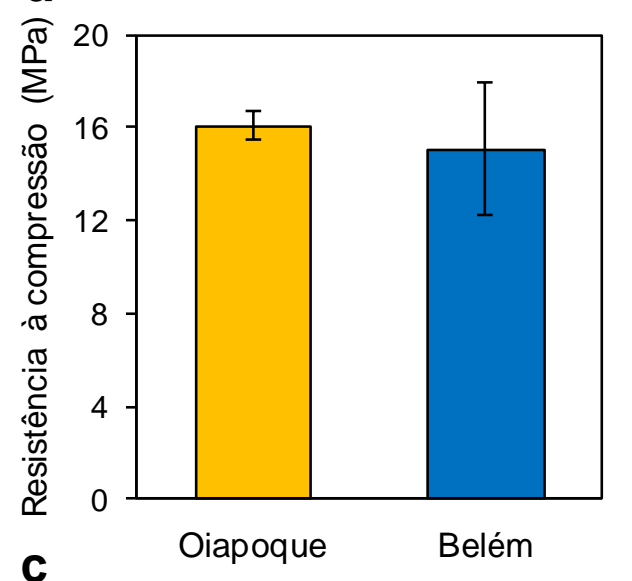

b

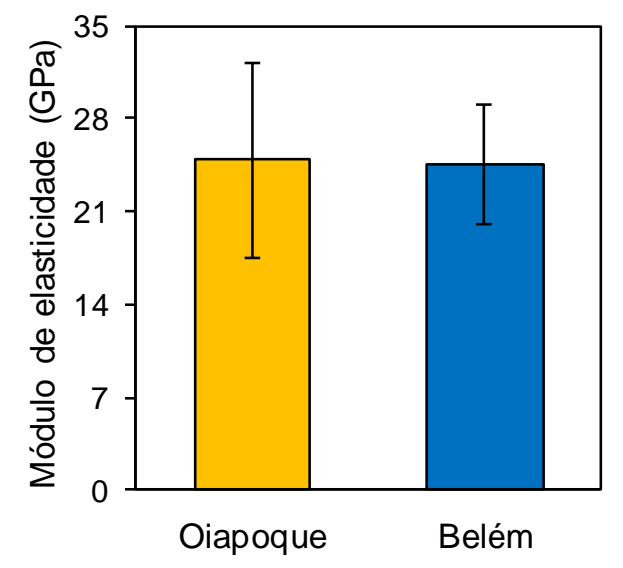

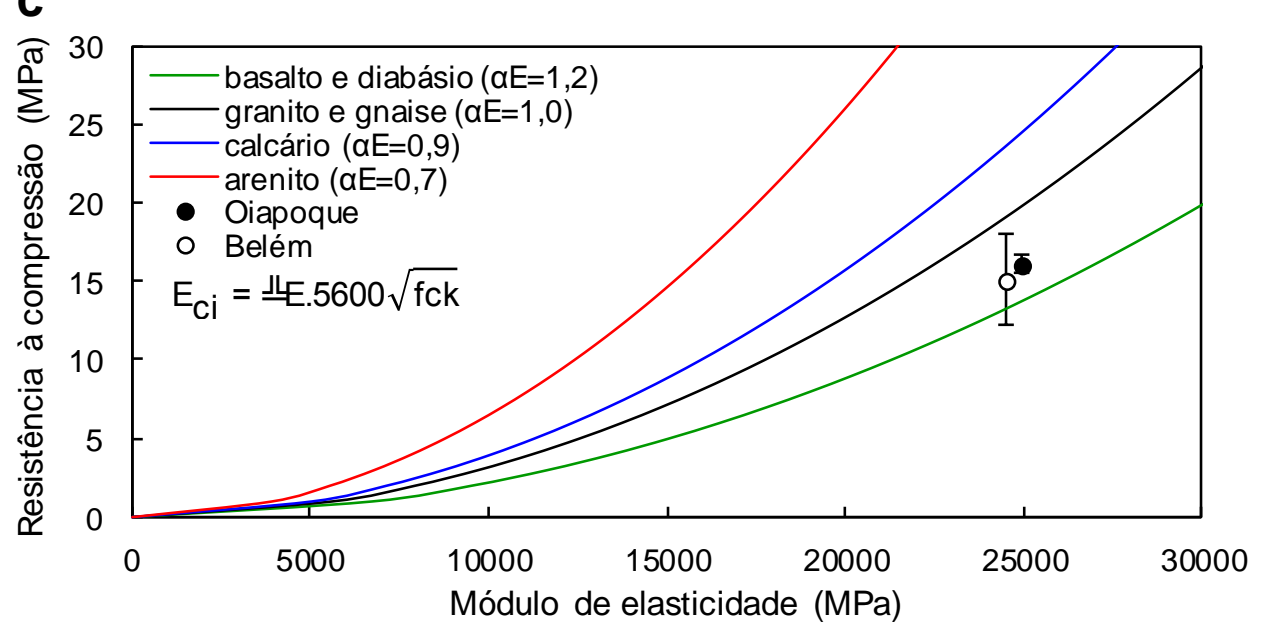

Figura 2: Propriedades mecânicas dos concretos - (a) resposta à resistência à compressão; (b) efeitos da origem do agregado no módulo de elasticidade e (c) módulo de elasticidade estimado (Eci) em relação à natureza do agregado, em função da resistência à compressão. Os valores experimentais de Oiapoque e Belém, estão representados como média \pm desvio padrão. $\alpha \mathrm{E}$ é o parâmetro em função da natureza do agregado que influencia o módulo de elasticidade, e fck é a resistência característica à compressão do concreto. 
O concreto produzido com o agregado do presente estudo apresentou um módulo de elasticidade que está localizado entre o agregado de origem basáltica e granítica quando comparado com os módulo de elasticidade estimado (Eci) da NBR 6118 (ABNT, 2014) [12], isso sugere que existem falhas na formulação dessas curvas que relacionam a origem mineralógica do agregado com o módulo de elasticidade do material, já que o agregado do presente estudo não está próximo da curva que representa sua origem mineralógica (curva vermelha da Fig. 2). Como os agregados são os principais constituintes do concreto e, tipicamente, ocupam entre $60 \%$ e $80 \%$ do volume do concreto [13] a origem mineralógica desse material acaba influenciando no módulo de elasticidade do concreto, quanto maior o módulo de elasticidade do agregado, maior o módulo de elasticidade do concreto. Tanto o agregado de Belém quando de Oiapoque apesar de terem propriedades físicas diferentes (granulometria) eles são da mesma origem. As propriedades do concreto no estado fresco e endurecido são influenciadas principalmente pela qualidade desses agregados, incluindo sua durabilidade a longo prazo e sua resistência [14;15]. O agregado de origem arenítica, que vem sendo cada vez mais utilizado como material de construção para a produção de concreto no mundo todo, pode realmente afetar as propriedades do concreto tanto no estado fresco quanto no estado endurecido [16]. Isso acontece, porque as propriedades geológicas da rocha sedimentar, que origina esse agregado são bastante diversas.

Da mesma forma que para a resistência à compressão e para o módulo, não houve diferença entre os concretos na taxa de absorção de cloretos (Fig. 3, a) e nem na carbonatação (teste T não pareado; $t(18)$ $=0,338 ; \mathrm{P}=0,739 ;$ Fig. 3. b), o padrão apresentado em relação à carbonatação nas amostras de concretos, foi semelhante (Fig. 3, c e d).

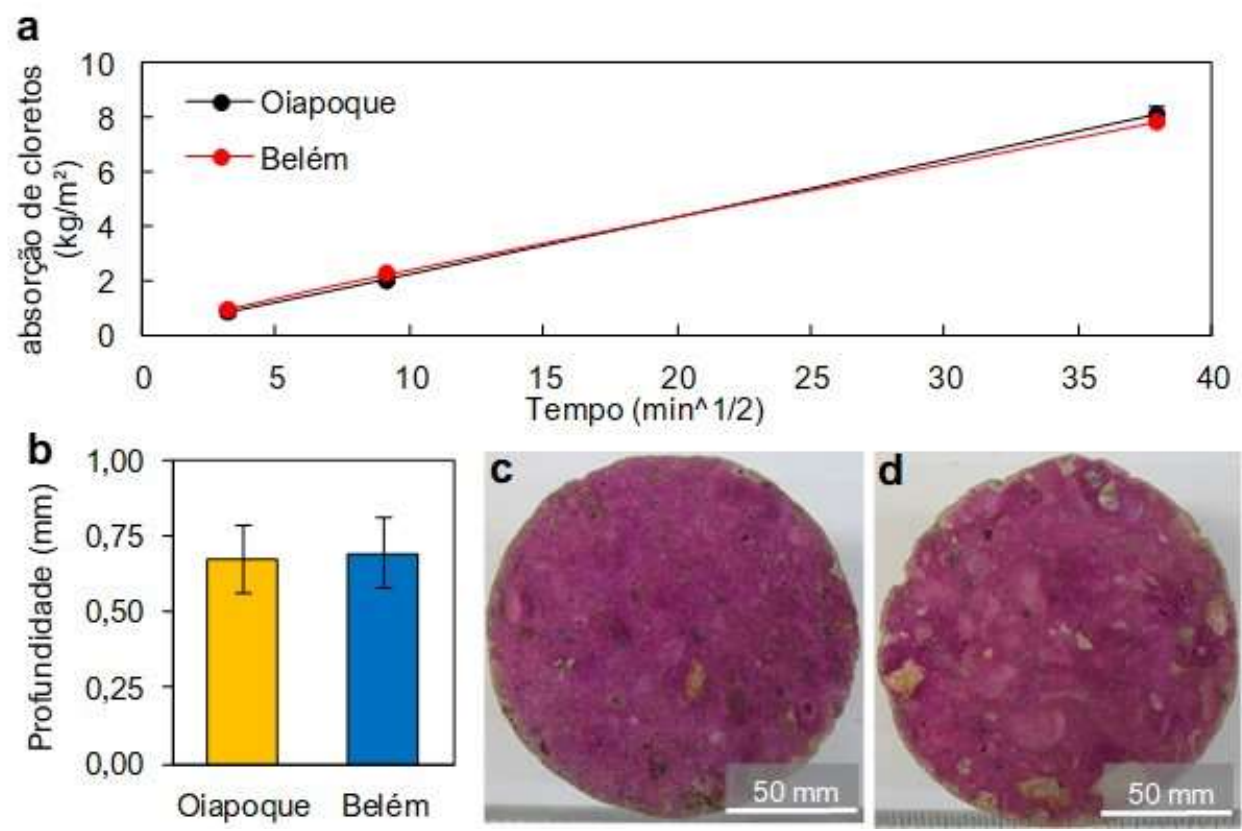

Figura 3: Absorção de cloretos para as amostras de concretos produzidas com o agregado de origem arenítica provenientes de diferentes regiões (Belém e Oiapoque) (a). Carbonatação acelerada para as amostras de concretos (b). c e d mostram as amostras de concreto Belém e Oiapoque respectivamente após sofrerem cisalhamento e receberem aplicação da solução de fenolftaleína para medição da profundidade de carbonatação.

Quanto a análise de difração de Raios-X realizada nas amostras correspondente à interface da matriz cimentícia e do agregado graúdo, esta identificou minerais que são comumente encontrados em concretos a base de cimento Portland (Figura 4), apresentando como as principais fases mineralógicas, a portlandita $\left(\mathrm{Ca}(\mathrm{OH})_{2}\right.$, American Mineralogist Crystal Structure Database - AMSCD 0000116) o quartzo ( $\mathrm{SiO}_{2}$, AMSCD 0004264) e o silicato de cálcio hidratado (xCaO.2 $\mathrm{SiO}_{2} \cdot \mathrm{yH}_{2} \mathrm{O}$ ou C-S-H AMSCD 0002329) (Figura 4). A portlandita junto com o C-S-H, são formados devido a hidratação dos produtos do clínquer [17], já o quartzo é proveniente da origem mineralógica do agregado [18]. 


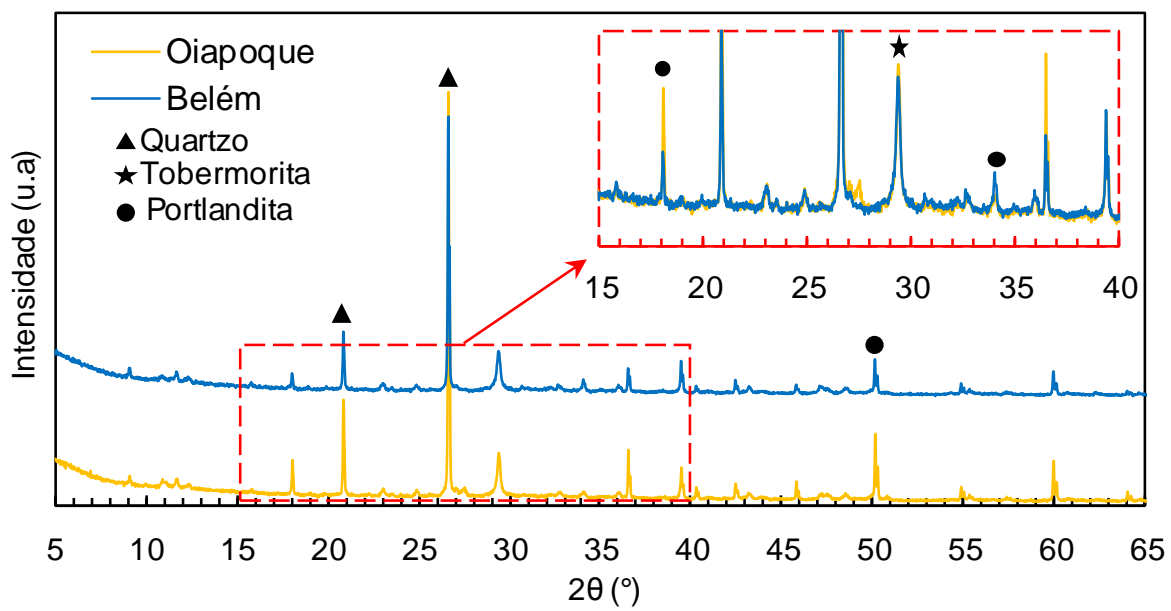

Figura 4: Difratogramas de raios- $X$ para as amostras de concretos produzidas com o agregado de origem arenítica provenientes de diferentes regiões (Belém e Oiapoque).

Em relação à microestrutura eletrônica de varredura dos concretos, estes apresentaram uma microestrutura densa, mas normalmente encontrada em compósitos formulados à base de matriz cimentícias. A Figura 5 a, apresenta a microestrutura da região localizada na zona de transição do concreto fabricado com o agregado disponível em Belém, já a Figura 5, b, apresenta a zona de transição do concreto fabricado com o agregado de Oiapoque. A Figura 5, c, apresenta uma microestrutura do concreto Oiapoque na interface agregado e matriz cimentícia, fica evidente com as Figuras 5, d, e, f e g, que a região superior da esquerda da Figura 5, c, é a morfologia da atuação do agregado de Oiapoque com a matriz cimentícia, isso é evidenciado pela elevada presença de silício acusado pelo mapeamento dos elementos, além disso, há ausência de cálcio e alumínio na região destacada. Da mesma forma, o mapeamento pode mostrar uma matriz com uma distribuição homogênea dos produtos de hidratação do cimento que podem ser compostos pela soma do mapa de cálcio, silício, alumínio e ferro. Algumas somas dos elementos em escuro podem representar vazios, a Figura $\mathrm{f}$ apresenta regiões de nucleação de alumínio (Al) que pode estar relacionada a formação de C-A-S-H principal produto de hidratação em cimentos que substituem parte do clínquer por material pozolânico, já que o cimento utilizado no presente estudo foi o CP IV - 32 . 

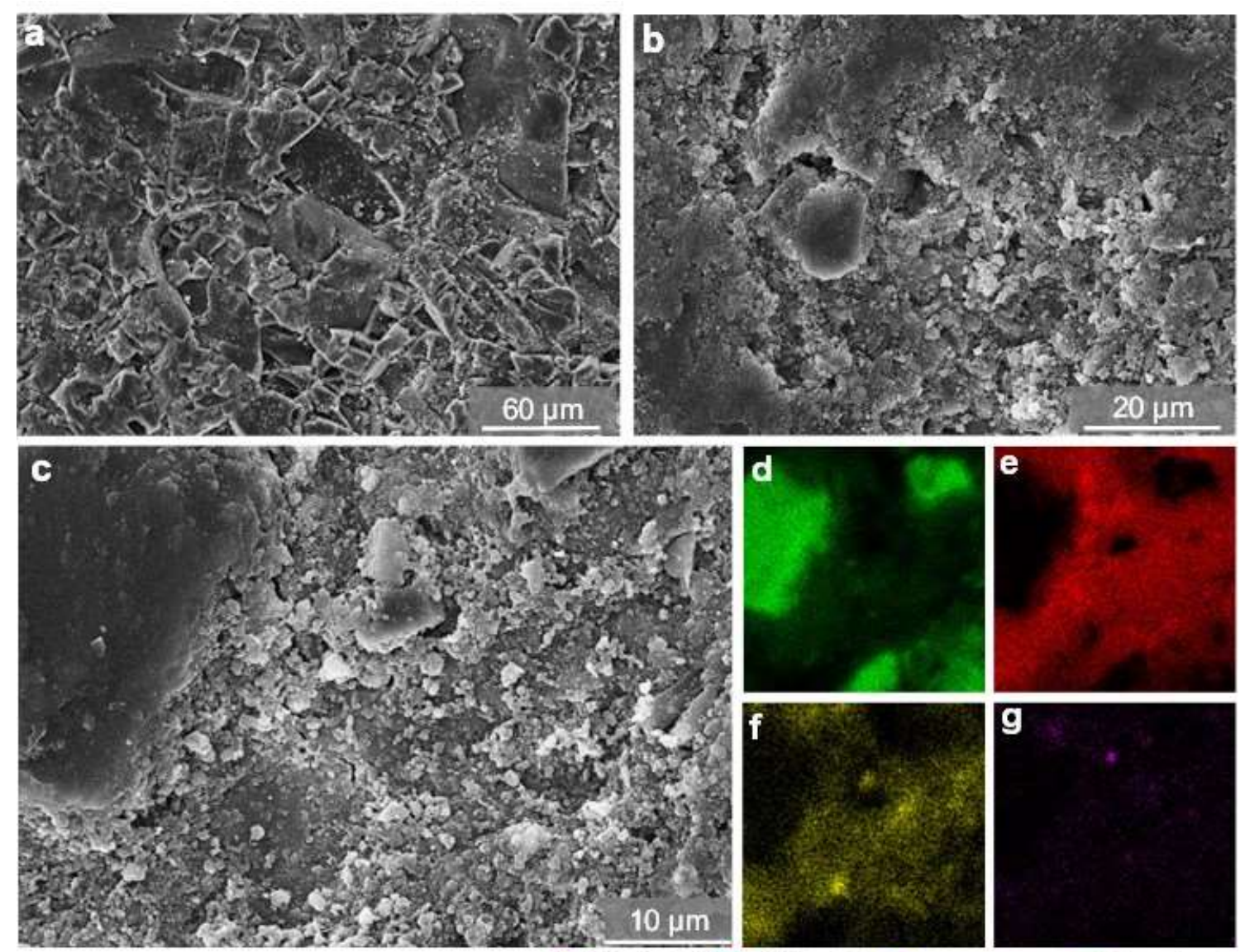

silicio $(\mathrm{Si})$

cálcio $(\mathrm{Ca})$ alumínio $(\mathrm{Al})$

ferro $(\mathrm{Fe})$

Figura 5: Microestrutura dos concretos. Em a é mostrado a microestrutura do concreto de Belém, em b e c é mostrado a microestrutura do concreto de Oiapoque. d, e, f e $\mathbf{g}$ apresenta o mapeamento dos elementos químicos de c.

\section{CONCLUSÕES}

A utilização do agregado de origem arenítica da região de Oiapoque não alterou a resistência à compressão e o módulo de elasticidade dos concretos em relação ao concreto produzidos com agregado disponibilizado comercialmente na região metropolitana de Belém. A média da resistência à compressão para o concreto de Oiapoque foi de 16,09 MPa e a média do módulo foi de $24,93 \mathrm{GPa}$, além disso não houve diferença entre os concretos quanto à taxa de absorção de cloretos ao longo do tempo e nem avanço na frente de carbonatação. A análise de difração de Raios X realizada nas amostras correspondente à interface da matriz cimentícia e do agregado graúdo, mostrou-se de acordo com as os padrões de DRX encontrados em amostras de concretos que utilizam o seixo de origem arenítica, apresentando como as principais fases mineralógicas, a portlandita $\left(\mathrm{Ca}(\mathrm{OH})_{2}\right)$, o quartzo $\left(\mathrm{SiO}_{2}\right)$ e o silicato de cálcio hidratado $\left(\mathrm{xCaO} \cdot 2 \mathrm{SiO}_{2} \cdot \mathrm{yH}_{2} \mathrm{O}\right.$ ou C-S-H), a microestrutura eletrônica de varredura dos concretos, apresentaram uma microestrutura densa, mas normalmente encontrada em compósitos formulados à base de matriz cimentícias. Esses achados servem como evidências empíricas para a validação da utilização de uma jazida de agregado na Região Amazônica, contribuindo para o desenvolvimento de obras de infraestrutura na região.

\section{AGRADECIMENTOS}

Os autores gostariam de agradecer ao Laboratório de Engenharia Civil da Universidade Federal do Pará (UFPA) pela colaboração nos ensaios mecânicos, ao Laboratório de Microanálise do Instituto de Geociência da UFPA pela colaboração na análise microestrutural dos concretos, e à Kelly Oliveira do Laboratório de Raios X, Análise Térmica e Dielétrica do Programa de Pós-Graduação em Física da UFPA pela colaboração na análise de DRX dos concretos. 


\section{BIBLIOGRAFIA}

[1] KRAUSMANN, F., WIEDENHOFER, D., LAUK, C., et al., "Global socioeconomic material stocks rise 23-fold over the 20th century and require half of annual resource use", Proceedings of the National Academy of Sciences, v. 114, pp. 1880-1885, 2017.

[2] UNITED NATIONS, DEPARTMENT OF ECONOMIC AND SOCIAL AFFAIRS, POPULATION DIVISION. "World Urbanization Prospects", The 2014 Revision, Highlights (ST/ESA/SER.A/352), 2014.

[3] TORRES, A., BRANDT, J., LEAR, K., et al., “A looming tragedy of the sand commons”, Science, v. 357, pp. 970-971, 2017.

[4] REGE, A. "Not biting the dust: using a tripartite model of organized crime to examine India's Sand Mafia”, International Journal of Comparative and Applied Criminal Justice, v. 40, pp. 101-121, 2015.

[5] VALERIANO, M. M., ROSSETTI, D. F. "Regionalization of local geomorphometric derivations for geological mapping in the sedimentary domain of central Amazônia", Computers \& Geosciences, v. 100, pp. 46-56, 2017.

[6] ASSSOCIAÇÃO BRASILEIRA DE NORMAS TÉCNICAS. Cimento Portland - Requisitos. NBR 16697. Rio de Janeiro, 2018.

[7] ASSSOCIAÇÃO BRASILEIRA DE NORMAS TÉCNICAS. Concreto - Determinação da consistência pelo abatimento do tronco de cone. NBR NM 67. Rio de Janeiro, 1998.

[8] ASSSOCIAÇÃO BRASILEIRA DE NORMAS TÉCNICAS. Concreto - Ensaio de compressão de corpos de prova cilíndricos. NBR 5739. Rio de Janeiro, 2018.

[9] ASSSOCIAÇÃO BRASILEIRA DE NORMAS TÉCNICAS. Concreto - Determinação dos módulos estáticos de elasticidade e de deformação à compressão. NBR 8522. Rio de Janeiro, 2017.

[10] REUNION INTERNATIONALE DE LABORATORIES D'ESSAIS ET MATERIAUX.

"Determination of the Capillary Absorption of Water of Hardened Concrete: TC 166 PCD", Materiaux and Constructions, v. 32, p. 178-179, Abr. 1999.

[11] REUNION INTERNATIONALE DE LABORATORIES D'ESSAIS ET MATERIAUX. TC 116PCD: "Permeability of concrete as criterion of its durability: tests for gas permeability of concrete. (RILEM Recommendation TC 116-PCD)", Materials and Structures, v. 32, p. 174-179, Apr 1999.

[12] ASSSOCIAÇÃO BRASILEIRA DE NORMAS TÉCNICAS. Projeto de estruturas de concreto Procedimento. NBR 6118. Rio de Janeiro, 2014.

[13] THOMAS, M. D. A., FOLLIARD, K. J., PAGE, C. L., et al., "Concrete aggregates and the durability of concrete. Durability of concrete and cement composites", Woodhead Publishing Limited and CRC Press, vol. 1, p. 247-281, 2007.

[14] METHA, P. K., MONTEIRO, P. Concreto: Microestrutura, propriedades e Materiais, 3. ed. São Paulo, IBRACON, 2014.

[15] NEVILLE, A. M. Tecnologia do concreto. Porto Alegre, Bookman, 2013.

[16] MACKECHNIE, J. R. "Shrinkage of concrete containing graywacke sandstone aggregate", ACI Materials Journal, v. 103, pp. 390-396, 2006.

[17] KUPWADE-PATIL, K., PALKOVIC, S. D., BUMAJDAD, A., et al., "Use of silica fume and natural volcanic ash as a replacement to Portland cement: Micro and pore structural investigation using NMR, XRD, FTIR and X-ray microtomography", Construction and Building Materials, v. 158, pp. 574590, 2017.

[18] QOKU, E., BIER, T. A., WESTPHAL, T. "Phase assemblage in ettringite-forming cement pastes: A $\mathrm{X}$-ray diffraction and thermal analysis characterization", Journal of Building Engineering, v. 12, pp. 3750, 2017.

\section{ORCID}

Agostinho Oliveira Júnior Maurílio Gomes Pimentel https://orcid.org/0000-0003-4678-7681 Marcelo de Souza Picanço https://orcid.org/0000-0002-5886-4544 https://orcid.org/0000-0001-7313-1229 